\title{
Management of neonatal testicular torsion: Which way to turn?
}

\author{
Luis A. Guerra, MD; Joshua Wiesenthal, MD; John Pike, MD; Michael P. Leonard, MD
}

See related article on page 380

\begin{abstract}
Objective: Perinatal testicular torsion (PTT) is a rare event with controversies surrounding its etiology, presentation, surgical management and sequelae. Our survey assessed the preferences of pediatric urologists with regard to its management.
\end{abstract}

Methods: Four cases of unilateral PTT and a questionnaire containing 11 questions about management of common clinical scenarios were mailed to 26 pediatric urologists. The answers were received anonymously and they were analyzed blindly.

Results: The response rate was $80 \%(21 / 26)$, with $90 \%$ (19/21) of respondents holding academic appointments. In the 2 first cases of PTT with a typical unilateral nonviable testis, $76 \%(16 / 21)$ and $67 \%(14 / 21)$, respectively, opted for surgery. A case of acute postnatal torsion resulted in $100 \%$ agreement to urgent scrotal exploration. In the case of an atrophic testis, none of the respondents opted for immediate surgery; yet, $38 \%(8 / 21)$ said they would proceed with a delayed orchiopexy of the contralateral testicle. In the question section, $10 \%(2 / 21)$ responded that they preferred to explore PTT immediately; whereas, 57\% (12/21) would delay surgical exploration for a few days until the neonate was better stabilized. One-third of participants (7/21) would not perform a surgical exploration but would just follow the child clinically. A scrotal incision for contralateral orchiopexy was preferred by $52 \%(11 / 21)$, while $48 \%(10 / 21)$ prefer a scrotal approach but would switch to an inguinal incision if a hydrocele were present. Operative intervention was favoured by $80 \%(8 / 10)$ and $46 \%(5 / 11)$ of those with less than and greater than 10 years of practice, respectively.

Conclusion: This survey revealed that $67 \%$ (14/21) of respondents preferred immediate exploration of a torted testis and contralateral orchiopexy, compared with the nonoperative approach. Scrotal incision for the exploration was preferred by most respondents. There was a trend to choose less aggressive treatment as the years of practice increase. Studies of more robust design, such as randomized controlled trials, are necessary to determine the natural history and outcomes of this uncommon type of testicular torsion.

CUAJ 2008;2(4):376-9

\section{Introduction}

Initially described in 1897 by Taylor ${ }^{1}$ in Britain and about 50 years later in North America by Campbell, ${ }^{2}$ perinatal testicular torsion (PTT) is a rare event with controversies surrounding its etiology, presentation, surgical management and sequelae. Initially, PTT was thought of as one distinct entity. Recently, however, it has been subcategorized as either occurring prenatally in utero or immediately postnatally. ${ }^{3}$ Prenatal torsion is marked by minimal to no discomfort and very localized findings. Conversely, postnatal torsion is an acute manifestation with considerable tenderness and swelling of a previously normal testicle. ${ }^{4} \mathrm{~A}$ review of the urological literature demonstrates no consistent pattern regarding the potential etiologies of PTT. Possible theories include difficult labour, breech presentation, high birth weight, an overreactive cremasteric reflex and multiparity..$^{3-6}$

Despite the type or mechanism of torsion, PTT is an unexpected finding for neonatologists and parents. Antenatal ultrasound is not sensitive in detecting this abnormality; thus, it is commonly diagnosed during the routine postnatal physical examination. The pediatric urologist is usually consulted in the first few hours of life and is faced with formulating a management plan. There is much controversy regarding the optimal management. This survey assessed the preferences of Canadian pediatric urologists with regard to the need for an operation, and the type and timing of an operation for PTT. Additionally, we attempted to determine whether number of years in practice had an effect on decisionmaking with regard to PTT.

\section{Methods}

Four standardized cases of unilateral PTT and a questionnaire containing 11 questions about management of common clinical scenarios were sent by mail to 26 pediatric urologists. In all 4 cases, participants were faced with 1 hard, enlarged, nonpainful, ischemic-appearing testicle and a normal contralateral testicle. In all but case 3 the findings were documented at birth. The 
respondents were asked to send their answers anonymously, and these were processed and analyzed blindly.

\section{Results}

The response rate was $80 \%(21 / 26)$, with $90 \%$ (19/21) of respondents holding academic appointments. The clinical cases and elected management approaches are shown in Table 1. In the first 2 cases demonstrating typical unilateral nonviable testes, $76 \%(16 / 21)$ and $67 \%(14 / 21)$, respectively, opted for surgery. The third case suggested an acute postnatal torsion, which resulted in $100 \%$ agreement with regard to urgent surgical exploration; however, 1 respondent pondered that he or she would not explore surgically if the torsion were longer than 12 hours. For the fourth case, in which an atrophic testis already existed, none of the respondents opted for immediate surgery; yet, $38 \%$ reported they would proceed with a delayed orchiopexy of the contralateral testicle.

In the section with 11 questions on preferences in the management of PTT, $10 \%(2 / 21)$ of the respondents answered that they would explore PTT immediately; whereas, $57 \%(12 / 21)$ would delay scrotal exploration for a few days until the neonate was better stabilized. One-third of participants (7/21) said they would not perform surgical exploration and that they would follow the child clinically, in which case the parents would be advised to bring the child back at the minimum abnormality of the contralateral testis. A scrotal incision for contralateral orchiopexy was preferred by $52 \%$ $(11 / 21)$, while $48 \%(10 / 21)$ preferred a scrotal approach but would switch to an inguinal incision if a hydrocele were present. When stratified by years in practice, $80 \%(8 / 10)$ of pediatric urologists who had been practising less than 10 years preferred an operative approach, and only $46 \%(5 / 11)$ of surgeons with more than 10 years of experience would operate.

\section{Discussion}

PTT is anxiety-provoking for both parents and physicians with regard to appropriate management. For obvious reasons, there are no randomized controlled trials comparing the efficacy of early surgical intervention with a nonoperative approach. PTT is also quite infrequent, and individual experiences are limited. The survey conducted by Das and Singer ${ }^{7}$ concluded that US pediatric urologists only encountered between 2 and 30 PTTs throughout their careers. Bilateral cases of torsion are even more rare,,$^{8-11}$ and the salvage rate of the affected testes is extremely low. Baglaj and Carachi ${ }^{12}$ recently reviewed the literature and found 48 cases of bilateral PTT. Despite prompt surgical intervention in 46 cases, only 3 testicles had postoperative arterial flow based on Doppler ultrasonography. We focused our survey on the management of unilateral cases, which are seen more frequently and raise more difficult management decisions. Interestingly, our survey summarizes the preferences of a group of academic pediatric urologists who are influencing the training of future urologists.

In agreement with Das and Singer's survey, most respondents to our survey would perform a scrotal exploration with a view to performing a contralateral orchiopexy. Stone and colleagues ${ }^{13}$ suggested that exploration of the torted testis has the benefit of confirming the torsion while ruling out other possible diagnoses. The rationale for this approach is supported by the increased likelihood of a

\begin{tabular}{|c|c|c|c|c|c|c|c|c|}
\hline \multicolumn{5}{|c|}{ Standardized case descriptions } & \multicolumn{4}{|c|}{$\begin{array}{l}\text { Selected treatment approach; } \\
\text { no. (and \%) of respondents }\end{array}$} \\
\hline Case & $\begin{array}{l}\text { Patient } \\
\text { age }\end{array}$ & $\begin{array}{l}\text { Ultrasound } \\
\text { results }\end{array}$ & Ipsilateral testis & $\begin{array}{c}\text { Contralateral } \\
\text { testis }\end{array}$ & $\begin{array}{l}\text { Immediate } \\
\text { surgery }\end{array}$ & $\begin{array}{l}\text { Delayed } \\
\text { surgery }\end{array}$ & $\begin{array}{l}\text { Conservative } \\
\text { follow-up }\end{array}$ & Other \\
\hline 1 & $2 \mathrm{~h}$ & No flow & Hard, enlarged, nonpainful & Normal & $6(29)$ & $10(47)$ & $5(24)$ & $0(0)$ \\
\hline 2 & $2 \mathrm{~h}$ & No flow & Hard, enlarged, nonpainful & $\begin{array}{l}\text { Normal with } \\
\text { hydrocele }\end{array}$ & $6(29)$ & $8(38)$ & $6(29)$ & $1(5)$ \\
\hline 3 & $11 d$ & No flow & Previous status unknown & Normal & $16(76)$ & $5(24)$ & $0(0)$ & $0(0)$ \\
\hline 4 & $3 d$ & No flow & Atrophic testis & Normal & $0(0)$ & $8(38)$ & $13(62)$ & $0(0)$ \\
\hline
\end{tabular}


contralateral extravaginal torsion during the first 2 months of life, which could lead to an anorchid state. The most common mechanism of PTT is extravaginal, in which the testis torts over the axis of the spermatic cord along with its tunica vaginalis. Since the tunica vaginalis in a newborn takes around 1 or 2 months to firmly attach to the inner wall of the scrotum, this period of time is critical and the child is subjected to an increased likelihood of an asynchronic torsion of the contralateral testis. Most of the recent literature strongly recommends early scrotal exploration and contralateral orchiopexy. ${ }^{12}$ The decision for intervention may be influenced in part by the level of uncertainty with regard to a possible contralateral torsion and in part to a result of the litigious medical environment in which pediatric urologists practice.

Only one-third of the respondents felt confident with the conservative approach and elected not to explore PTT. After 2 months of life, when the tunical layers fuse, the mechanism of torsion is intravaginal and related to the bell clapper deformity in which the testis has a more horizontal lie and greater mobility. After this tunical layer fusion, the likelihood of contralateral torsion becomes equal to the general population. Advocates of the nonsurgical approach rely on the very low occurrence of contralateral torsion and the various surgicaland anesthetic-related risks in the neonatal period. ${ }^{14,15}$ Performing an orchiopexy in a newborn with delicate anatomy has a higher chance of injury to the single testis. Furthermore, if the parents are educated about how contralateral torsion presents, they could bring the child to the emergency department at the first sign of abnormality and there would be a chance of saving the testis. Parrott and Woodard ${ }^{16}$ argue that urological surgery is safe in a neonate, as scrotal exploration and orchiopexy are not lengthy procedures and intraoperative risks are minimal. A scrotal incision for contralateral orchiopexy was preferred by $52 \%$ of respondents; $48 \%$ indicated that their approach would be scrotal, but that they would change it to an inguinal incision if an ipsilateral hydrocele was present. The decision to change the surgical approach to an inguinal incision for excision of a hernia sac is adequate; however, it involves a more complex surgical repair and carries a higher risk of injury to the spermatic cord.

Interestingly, when respondents were stratified by their experience, there was a trend to be more conservative among those who were in practice for more than 10 years. This conservative approach likely results from the culmination of experience with similar challenging cases. Although our survey showed a trend toward surgical intervention in newborns with PTT, this indication is still empirical, and risks and benefits of both approaches should be fully discussed with the parents. ${ }^{17}$

Some limitations of our study were identified. Our survey was conducted on 4 cases of PTT and 11 questions; however, this may not represent comprehensively the scenarios that are seen in clinical practice. Pictures showing the physical findings of the scrotum and/or ultrasound images of the cases could possibly result in a more accurate assessment by the respondents. Although the answers were treated anonymously, interviewer bias may still have been introduced since some respondents could be concerned about being identified.

\section{Conclusion}

Management of PTT is a controversial topic and there are no evidence-based guidelines in the literature. This survey revealed that $67 \%$ of respondents preferred immediate exploration of the torted testis and contralateral orchiopexy, compared with the nonoperative approach. There is a trend to be less aggressive as the physicians' years of practice increase. Scrotal incision for the exploration was preferred by most respondents. This study shows the preferences of a group of Canadian pediatric urologists who work in academic centres and are influencing the teaching of future practitioners. Studies of more robust design, such as randomized controlled trials, are necessary to determine the natural history and outcomes of this uncommon type of testicular torsion.

From the Division of Paediatric Urology, University of Ottawa, Children's Hospital of Eastern Ontario, Ottawa Ont.

This article has been peer reviewed.

Competing interests: None declared.

\section{References}

1. Taylor MR. A case of testicle strangulated at birth; castration; recovery. BMJ 1897;1:458.

2. Campbell MF. Torsion of the spermatic cord in the newborn infant. J Ped 1948;33:323.

3. Brandt MT, Sheldon CA, Wacksman J, et al. Prenatal testicular torsion: principles of management. J Urol 1992;147:670-2. 
4. Gillenwater JY, Burros HM. Torsion of the spermatic cord in utero. JAMA 1966;198: $1123-4$.

5. Leach GE, Masih BK. Neonatal torsion of the testicle. Urology 1980;16:604-5.

6. Reeves HH, Sigler RM, Hahn HB Jr, et al. Torsion of the spermatic cord in the newborn. Am J Dis Child 1965;110:676-7.

7. Das S, Singer A. Controversies of perinatal torsion of the spermatic cord: a review, survey and recommendations. J Urol 1990;143:231-3.

8. Castilla EE, Sod R, Anzorena 0 , et al. Neonatal testicular torsion in two brothers. J Med Genet 1975;12:112-3.

9. Papadatos C, Moutsouris C. Bilateral testicular torsion in the newborn. J Pedod 1967;71:249-50

10. Atallah MW, Ippolito JJ, Rubin BW. Intrauterine bilateral torsion of the spermatic cord. J Urol 1976;116:128-9.

11. Kay R, Strong DW, Tank ES. Bilateral spermatic cord torsion in the neonate. J Urol 1980;123:293

12. Baglai $M$, Carachi R. Neonatal bilateral testicular torsion: a plea for emergency explo- ration. J Urol 2007; 177:2296-9

13. Stone KT, Kass EJ, Cacciarelli AA, et al. Management of suspected antenatal torsion: What is the best strategy? J Urol 1995; 152:782-4.

14. Warner $L 0$, Teitelbaum DH, Caniano DA, et al. Inguinal herniorrhaphy in young infants: perianesthetic complications and associated preanesthetic risk factors. J Clin Anesth 1992; $4: 455-61$

15. Tobias JD, Lowe $S, O^{\prime} D e l l l$ N, et al. Continuous regional anaesthesia in infants. Can J Anaesth 1993;40:1065-8.

16. Parrott TS, Woodard JR. Urologic surgery in the neonate. J Urol 1976;1 16:508-9.

17. Yerkes EB, Robertson FM, Gitlin J, et al. Management of perinatal torsion: Today, tomorrow or never? J Urol 2005;174:1579-82.

Correspondence: Dr. Luis Guerra, Children's Hospital of Eastern Ontario (Pediatric Urology), 401 Smyth Rd., Ottawa ON KIH 8Ll; Iguerra@uottawa.ca

\title{
We welcome your comments on the journal and on specific articles.
}

\author{
All letters will be considered \\ for publication in the journal.
}

\section{Send your letters to the Editor-in-Chief at journal@cua.org}

CUAJ JAUC

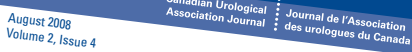

Are we on the rig Are we on the right track?

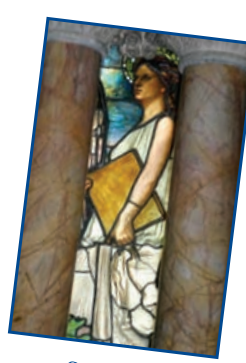

CanMEDS:

Août 2008
Volume 2, Numéros

Treatinglasty: the McMaster experience

LUTS and BPH children with stones 